\title{
Handling Insulin-Related Emotions
}

Sanjay Kalra $\cdot$ Komal Verma

Received: March 5, 2018 / Published online: May 28, 2018

(C) The Author(s) 2018

\section{ABSTRACT}

This article discusses a simplified, yet comprehensive approach to handle complex varieties of emotions related to insulin injections prescribed to patients with diabetes. Diabetes management requires balancing of biomedical and psychosocial complexities, so that varied emotions faced by individuals with diabetes which lead to undesirable reactions/behavior are understood and managed. This realization has inspired useful mnemonics such as OPEN OUT, SHAKTI, ASHA/HOPE, SHANTI/SHALOM, and LISTEN. These, if used in diabetes care practice, will make insulin acceptable and well tolerated.

Keywords: Insulin; Diabetes; Diabetes distress; Mnemonics; Motivating; Psychosocial; Therapeutic patient education

Enhanced digital features To view enhanced digital features for this article go to https://doi.org/10.6084/ m9.figshare.6283097.

S. Kalra $(\bowtie)$

Department of Endocrinology, Bharti Hospital, Karnal, India

e-mail: brideknl@gmail.com

K. Verma

Amity Institute of Behavioural and Allied Sciences, Amity University Rajasthan, Jaipur, India

\section{INTRODUCTION}

The mention of insulin injections creates a complex variety of emotions in persons with diabetes. Denial, distress or anxiety, helplessness, and anger or hatred may all act as obstacles to timely initiation of insulin therapy. Not infrequently, health care professionals feel incapable of handling these emotions, and display inertia in prescribing insulin. The unwarranted delay leads to avoidable exposure to hyperglycemia, which contributes to development of chronic complications. This is unfortunate, as the salutogenic properties of insulin have been known to medical science for nearly a century. We therefore need to strengthen our communication and motivation skills, so that we can respond to the various emotions that our patients display, when advised to begin or intensify insulin therapy.

\section{MNEMONICS OF UTILITY}

Excellent books and reviews have been written on behavioral approaches in diabetes care and on bridging barriers to insulin therapy $[1,2]$. We suggest simple mnemonics which can assist the health care professional in managing "difficult" emotions. Using words from English, Sanskrit, and Hebrew, we juxtapose appropriate responses to the commonly experienced emotional challenges. This article does not contain any 
studies with human participants or animals performed by any of the authors.

Asking persons in denial to OPEN OUT, we offer SHAKTI (strength) to those who feel helpless, ASHA (hope) to those in distress or suffereing from anxiety or depression, and SHANTI or SHALOM (peace) to neutralize anger (Table 1). If there is one piece of advice we would like to share, it would be to LISTEN to patients: this mnemonic, if followed sincerely, contributes significantly to satisfying and successful diabetes care delivery (Table 1).

Though these mnemonics appear simple, their importance cannot be underestimated. While newer insulin regimens, preparations, concentrations, and delivery devices are welcome, their utility is dependent upon acceptance of, and adherence to, injectable therapy [3]. The tools shared in this editorial act as a learning and teaching tool as well as an aid to clinical practice. If internalized and assimilated in routine clinical conversations, they will contribute to better outcomes in diabetes care.

\section{SCIENTIFIC BASIS}

The importance of psychological therapies in the management of diabetes is well documented. Equally well understood is the need for further study and research in this domain [4]. Randomized controlled trials of robust design [5] and exhaustive systematic reviews and metaanalyses [6] have shown that cognitive behavioral therapy and other psychological interventions can improve glycemic control in both type 2 and type 1 [7] diabetes. These developments have spurred an interest in "new wave" therapies with novel nomenclature [8]. It is accepted, however, that there is not much difference in the implementation of these therapies in the clinical setting [9]. While underlying theory may differ, their results are similar.

It therefore makes sense to focus more on the content of psychological interventions rather on their onomastics. It also behooves diabetes care professionals to focus on good communication skills as a means of enhancing diabetes care acceptance and adherence [10]. The use of simple mnemonics has been found to improve
Table 1 Mnemonics to help in handling emotions relating to insulin use

\section{Dealing with denial: OPEN OUT}

O open-ended conversation

$\mathrm{P}$ points of concern

E equipoise in information

$\mathrm{N}$ nonjudgmental suggestion

O offer time to reflect

U understand other's opinion

$\mathrm{T}$ therapeutic patient education

\section{Dealing with hopelessness: SHAKTI}

$S$ support with a smile

$\mathrm{H}$ holding hands, helpfully

A assess limitations/strengths

K “kreate” (create) bridges over barriers

$\mathrm{T}$ therapeutic patient education

I identify sources of support

Dealing with anxiety and distress: ASHA/HOPE

A acknowledgement of fears and concerns

$S$ strength mapping-self, society, system (health care)

$\mathrm{H}$ help build resources

A anticipate challenges, plan ahead

$\mathrm{H}$ help acknowledge fears and concern

$\mathrm{O}$ offer optimism and strength

P prepare pragmatic plan of action

E explore available resources and expand upon them

Dealing with ANGER: SHANTI/SHALOM (peace)

$S$ stop for a second

$\mathrm{H}$ hear out the person

A appreciate other's viewpoint

$\mathrm{N}$ note fears and concerns

$\mathrm{T}$ "translate"/paraphrase core issues

I intervention to be planned

$S$ stop for a second

$\mathrm{H}$ hear out the person 
Table 1 continued

A appreciate other's viewpoint

$\mathrm{L}$ list fears and concerns

O optimism for resolution

$\mathrm{M}$ monitoring and motivation

Take-home message: LISTEN

$\mathrm{L}$ list patient's concerns and fears

I information equipoise

$S$ share sources of support

$\mathrm{T}$ therapeutic patient education/teamwork

E empathic understanding/expression

$\mathrm{N}$ neutral nonjudgmental communication

health care delivery and enhance patient understanding as well as adherence $[11,12]$.

\section{Dealing with Denial: OPEN OUT}

Denial is a negative coping mechanism exhibited by many persons with acute or chronic illness. This is also noted when insulin is prescribed. Persons may downplay their symptoms or laboratory abnormalities in order to avoid injectable therapy. OPEN OUT offers a means of breaking the vicious cycle of denial and poor glycemic control. We should strike up an open-ended conversation, so as to glean the patient's points of concern and reasons for denying the need for insulin. Myths and misunderstandings related to insulin must be explored. Usually these are propagated by hearsay. These and other barriers to insulin use must be overcome by creating specific bridges $[2,3]$. Equipoise (or balance) in information should be maintained, in a gradual and friendly manner.

Once the patient has the basic information necessary for rational decision-making, we can offer appropriate suggestions, in a neutral or nonjudgmental manner. Unless there exists an immediate threat to life, limb, or organ that can be resolved only by insulin, we should offer time to the patient to reflect upon our suggestions, and understand his or her opinion. This strategy should be accompanied by a continuous process of therapeutic patient education (TPE) [13].

\section{Dealing with Hopelessness: SHAKTI (Strength)}

Some patients may experience a sense of complete helplessness or inability to cope with insulin treatment. This perceived lack of selfefficacy can be corrected by offering SHAKTI (in Indian languages, shakti stands for strength). This is achieved by offering support with a simple and helpful handholding to allow realistic assessment of the patient's limitations and strengths. This facilitates $k(\mathrm{c})$ reation of bridges over barriers to insulin use. As with other emotions, TPE forms an integral part of therapy. With SHAKTI, however, one must also identify (and utilize) sources of support for the patient. These may include family, friends, peer educators, diabetes care professionals, religious leaders, and society at large.

\section{Dealing with Distress: ASHA/HOPE}

Anxiety and distress are often encountered during conversations about insulin [14]. These fears and concerns are countered by ASHA ("hope" in Indian languages). The first step is to acknowledge the patient's stress, and then help them map their strengths. Once a realistic strength mapping is done, we can work with them to help build, optimize, and utilize their resources. We must be vigilant in anticipating challenges and obstacles to insulin use, and planning ahead to mitigate them.

HOPE is the antidote to distress. HOPE is a checklist which helps us recognize and acknowledge the fears and concerns of our patient. This allows us to offer optimism and strength, while preparing a pragmatic plan of action for diabetes care. Hope is bolstered by exploration and utilization of available social 
and medical resources to assist in insulin administration.

\section{Dealing with Anger: SHANTI/SHALOM (Peace)}

One of the most difficult emotions to tackle is anger or hatred. This usually occurs as a result of misdirected "transference" of emotions. Though anger or hatred is for the diagnosis of diabetes, and resultant need for insulin, the emotions get directed against the messenger, i.e., the diabetes care professional, who diagnoses diabetes and recommends insulin.

The Indian word shanti and Hebrew word shalom, which mean peace, facilitate defusion of anger. SHANTI stands for the following strategy: stop for a second, hear out the person, appreciate the other's viewpoint, note fears and concerns, "translate' or paraphrase core issues, and then plan appropriate interventions.

The mnemonic SHALOM reminds us to stop for a moment, hear out the other person, and appreciate their viewpoint. We can then identify, list, and prioritize their concerns and offer optimism and support to resolve these issues. Constant motivation and monitoring help complete the SHALOM mnemonic.

\section{One Approach Fits All: LISTEN}

There is one approach, however, which is applicable to all insulin emotions. This is the art of being able to LISTEN. Listening is the first pillar of "diabetes therapy by ear," which includes active listening, empathic counseling, and support in filtering hearsay (or misinformation) from scientific facts $[13,14]$.

The LISTEN mnemonic suggest that we list the patient's concerns and fears, whether founded or unfounded. Once we are aware of his or her knowledge gaps, we work to achieve information equipoise. This is done by sharing trusted sources of support and advice, and offering TPA. Teamwork is necessary to achieve this, as are empathic understanding and expression of our empathy. We should be able to convey to the patient that we all work together as a team, the person with diabetes being the captain of our ship. Our teamwork will be successful only if we are able to understand and empathize with each other, and support each other. We must ensure that we have optimal knowledge of each other's strengths and shortcomings, in both biomedical and psychosocial domains. All this communication should be carried out in a neutral nonjudgmental manner.

\section{SUMMARY}

As diabetes care professionals, we work daily to motivate patients to accept, initiate, and adhere to insulin therapy. Usually, we succeed. Sometimes, we don't. Most of the barriers we face relate to the emotional or psychological state of the patient rather than the biomedical nature of diabetes or the pharmacological characteristics of insulin. We have found the mnemonics OPEN OUT, SHAKTI, HOPE, SHALOM, and LISTEN helpful in our clinical practice and hope that our readers do, too. We encourage our readers to share their best practices in diabetes and endocrine care as well.

\section{ACKNOWLEDGEMENTS}

We acknowledge the inspiration and guidance we have gained from the book Approaches to Behavior, by Janis Roszler and Wendy Satin Rapaport.

Funding. No funding or sponsorship was received for this study or publication of this article.

Authorship. All named authors meet the International Committee of Medical Journal Editors (ICMJE) criteria for authorship for this article, take responsibility for the integrity of the work as a whole, and have given their approval for this version to be published.

Disclosures. Both authors, Sanjay Kalra and Komal Verma, do not have any disclosures relevant to the topic of this manuscript. 
Compliance with Ethics Guidelines. This article does not contain any studies with human participants or animals performed by any of the authors.

Open Access. This article is distributed under the terms of the Creative Commons Attribution-NonCommercial 4.0 International License (http://creativecommons.org/licenses/ by-nc/4.0/), which permits any noncommercial use, distribution, and reproduction in any medium, provided you give appropriate credit to the original author(s) and the source, provide a link to the Creative Commons license, and indicate if changes were made.

\section{Glossary}

$\begin{array}{ll}\text { SHAKTI } & \text { Strength } \\ \text { ASHA } & \text { Hope } \\ \text { SHANTI, SHALOM } & \text { Peace }\end{array}$

\section{REFERENCES}

1. Roszler J, Rapaport WS. Approaches to behavior. Alexandria: American Diabetes Association; 2015.

2. Kalra S, Ghosal S, Shah P. Consensus on bridges for barriers to insulin therapy. J Assoc Phys India. 2017;65(3):23-30.

3. Tandon N, Kalra S, Balhara YP, et al. Forum for injection technique and therapy expert recommendations, India: the Indian recommendations for best practice in insulin injection technique, 2017. Indian J Endocrinol Metab. 2017;21(4):600.

4. Delamater AM, Jacobson AM, Anderson B, et al. Psychosocial therapies in diabetes: report of the Psychosocial Therapies Working Group. Diabetes Care. 2001;24(7):1286-92.
5. Safren SA, Gonzalez JS, Wexler DJ, et al. A randomized controlled trial of cognitive behavioral therapy for adherence and depression (CBT-AD) in patients with uncontrolled type 2 diabetes. Diabetes Care. 2014;37(3):625-33.

6. Ismail K, Winkley K, Rabe-Hesketh S. Systematic review and meta-analysis of randomised controlled trials of psychological interventions to improve glycaemic control in patients with type 2 diabetes. Lancet. 2004;363(9421):1589-97.

7. Ismail K, Thomas SM, Maissi E, et al. Motivational enhancement therapy with and without cognitive behavior therapy to treat type 1 diabetes: a randomized trial. Ann Intern Med. 2008;149(10):708-19.

8. Hofmann SG, Sawyer AT, Fang A. The empirical status of the "new wave" of cognitive behavioral therapy. Psychiatr Clin. 2010;33(3):701-10.

9. Fabricatore AN. Behavior therapy and cognitivebehavioral therapy of obesity: is there a difference? J Am Diet Assoc. 2007;107(1):92-9.

10. Kalra S, Kalra B. Communication in diabetes care. J Pak Med Assoc. 2017;67(12):1946-8.

11. Reid JC, Klachko DM, Kardash CA, Robinson RD, Scholes R, Howard D. Why people don't learn from diabetes literature: influence of text and reader characteristics. Patient Educ Couns. 1995;25(1):31-8.

12. Pyke DA. How to live with diabetes. Proc R Soc Med. 1963;56(9):860.

13. Mazzuca SA. Does patient education in chronic disease have therapeutic value? J Chronic Dis. 1982;35(7):521-9.

14. Kalra S, Verma K, Singh YB. Management of diabetes distress. J Pak Med Assoc. 2017;67(10):1625-7. 